\title{
ACTIVIDADES DEL DEPARTAMENTO DE ESPAÑOL DEL INSTITUTO DE TRADUCTOLOGÍA, 2010-2015
}

Durante el año 2010, los miembros del Departamento de Español del Instituto de Traductología de la Facultad de Filosofía y Letras de la Universidad Carolina de Praga realizaron las siguientes actividades académicas: La PhDr. Slavomíra Ježková, CSc. se interesó por el tema del lenguaje especializado y redactó los siguientes dos trabajos: "La prononciation et la langue de spécialité", in: Brána jazyků otevřená. Vybrané lingvistické, lingvopedagogické a literární aspekty pro nové milénium, pp. 124-129 y "Le Cadre européen commun de référence et la langue de spécialité", Forlang, pp. 53-58.

La Prof. PhDr. Jana Králová, CSc. organizó el congreso Encuentro checo-español: Posibilidades y límites de la comunicación intercultural, celebrado del 16 al 17 de abril 2010, por la Facultad de Filosofía y Letras de la Universidad Carolina de Praga. Además, publicó en el número 12 de Hermēneus. Revista de Traducción e Interpretación el artículo "El texto traducido es un texto difundido o un quehacer (casi) olvidado", pp. 1-9. En el evento Den s překladem llevado a cabo en la Universidad de Ostrava presentó la ponencia "Od výuky jazyka k didaktice překladu a tlumočení aneb historia magistra vitae" [De la enseñanza de la lengua a didáctica de la traducción e interpretación, o sea, historia magistra vitae]. En noviembre ofreció un ciclo de conferencias de la teoría checa de la traducción en la Universidad de León y en los Encuentros Complutenses en torno a la traducción, celebrado en Madrid, presentó la ponencia "Estudio de traducciones del texto dramático: impulsos teóricos".

El Doc. PhDr. Miloslav Uličný ha abordado en distintos trabajos el tema de la historia de la traducción. En la reseña Historia de la traducción de Eugenio Oneguin al checo: "Stanislav Rubáš, Já píši Vám. Evžen Oněgin v českých překladech", in: Herméneus: Revista de traducción, 12, 2010, pp. 281-283, informa sobre una decena de traducciones checas del poema mencionado evaluada por el autor del libro y sobre el desarrollo de los métodos traductivos checos del mismo, tanto como ofrece una breve comparación con la traducción más reciente del poema al español. En el artículo "Drzé čelo lepší než poplužní dvůr. Z práce O českých překladech a "překladech" Dona Quijota", in: Plav: měsíčník pro světovou literaturu, 7-8, VI, 2010, pp. 81-86, analiza la traducción del Quijote realizada por Marie Luisa Kuhnlová como plagio de las traducciones de Josef Bojislav Pichl (tomo I) y Kristián Stefan (tomo II). A continuación, ha escrito el prólogo Nezvěstný Bernard Rambousek de Karel Hynek Mácha, Máj/Mai, Praha: Splav!, 2010, pp. 5-31, para la publicación bilingüe de la traducción alemana del poema Máj realizada por Bernard Rambousek. Él mismo ha vertido el poema al español publicándolo en una edición bilingüe Mácha, Karel Hynek, Máj/Mayo, Praha, Jalna, 2010. Del poema, de sus traducciones y de la vida del poeta se ocupa en tres textos diferentes: en el epílogo "Máchovy Máje”, pp. 77-88; en el epílogo de Mayo de Mácha en español, pp. 89-93; y en el artículo "Vedlejší efekt: Mácha's Mai”, Plav: měsíčník pro světovou literaturu, 1, VI, 2010, pp. 49-54.

El Lic. Miguel Cuenca participó en el ya mencionado congreso Encuentro checo-español: Posibilidades y límites de la comunicación intercultural, con la ponencia "Překladovost y posun: ¿causa o consecuencia?" Posteriormente, entre el 11 y el 13 de noviembre, intervino en los XIII encuentros complutenses en torno a la traducción, organizados por el Instituto Universitario de Lenguas Modernas y Traductores, Facultad Complutense de Madrid con la comunicación "La posición de la literatura checa en el polisistema literario español (1939-2000)", así como en el $X V$. mezinárodní setkání romanisti̊, organizado por la Facultad de Filosofía de la Universidad Palacký, Olomouc, el 26 y 27 de noviembre, presentando la ponencia "La literatura checa y el polisistema literario español". En el ámbito de las publicaciones, mencionemos la reseña sobre el trabajo de Juan Antonio Albaladejo Martínez La didáctica de la 
traducción en Europa, editada en el número VI de Lingua Viva, pp. 66-67.

En cuanto a las memorias de licenciatura, Lenka Melicharová presentó Rétorické figury $v$ překladech současné venezuelské publicistiky [Figuras retóricas en las traducciones del periodismo venezolano actual]. Hablando de los trabajos de Fin de Grado, Andrea Bačíková concluyó la traducción comentada Alicante y su provincia; Romana Elstnerová, La vida cotidiana de los españoles y Petra Vavroušová, España en el contexto del turismo internacional.

En lo que se refiere al programa Erasmus, cinco alumnos de la sección de español pudieron disfrutar de una estancia de estudios en distintas universidades españolas, acogiéndose a las becas de este programa.

Durante el año 2011, los miembros del Departamento de Español del Instituto de Traductología de la Facultad de Filosofía y Letras de la Universidad Carolina de Praga realizaron las siguientes actividades académicas:

La Prof. PhDr. Jana Králová, CSc. llevó a cabo, como editora, la publicación del libro Posibilidades y límites de la comunicación intercultural, Praha, Karolinum, 2011 en el que también apareció su artículo "Veintidós caras de la comunicación intercultural", pp. 7-10. Los siguientes trabajos presentan unos de los temas más frecuentes en su investigación, o sea, las líneas de investigación de los teóricos de la traducción Santoyo y Levý: J. C. "Santoyo, La traducción medieval en la Península Ibérica (siglos III-XV)", in: Écho des études romanes, 2011, 7, 2, pp. 109-111, y "Experiencias de la traducción de obra de Jiří Levý al español", in: Studia Romanica Bratislaviensia, 2011, 10. "Nuevas teorías, modelos y su aplicación en lingüística, literatura, traductología y didáctica en los últimos 20 años", pp. 175-184. Además, publicó los siguientes estudios y artículos: "La multifacética realidad del lenguaje" in: Lorenzo Hervás, 2011, n. 20, pp. 299-310; "Možnosti a meze mezikulturní komunikace”, in: Vědecký výzkum a výuka jazyků IV, 2011, pp. 25-33; "Traducir traductología”, in: Philologia XXI, Supplementum II, 2011, pp. 255-259; seguido de "Observaciones sobre la recepción de las actividades de los franciscanos en la cultura checa", in: Lingua, cultura e discorso nella tradizione dei francescani, 2011, pp. 789-794, y por último "Translation Studies in the First Years of Slovo a slovesnost (SaS)", in: Acta Universitatis Carolinae - Philologica, 2/2011, 8, pp. 115-124.
El Doc. PhDr. Miloslav Uličný ha abordado en distintos trabajos el tema de la historia de la traducción. En la ponencia "Metro, rima y norma de la época como móviles de manipulación en las versiones checas del romancero español (Tradición y método moderno)", in: Encuentros 2010. Volumen III. Traducción: ¿Manipulación o transformación necesaria? Estudios coordinados por Gerardo Beltrán y Katarzyna Dluzniewska-Loś, Varsovia: Instituto de Estudios Ibéricos e Iberoamericanos de la Universidad de Varsovia, 2011, pp. 159-167, pronunciada en la conferencia de Varsovia en octubre de 2010 y publicada en la antología de la misma, enfoca la problemática de la traducción poética. Con motivo del 200 aniversario del comienzo de la lucha anticolonial en México, presentó la ponencia "Literatura mexicana en las traducciones checas". In: Las Relaciones Checo-Mexicanas (Ibero-Americana Pragensia - Supplementum 26/2011), Editorial Karolinum, Praha, 2011, pp. 201-222, en la conferencia organizada por el Centro de Estudios Iberoamericanos de Praga en octubre de 2010. En el artículo "Don Quijote - magnet českých plagiátorů” in: PLAV: Měsíčník pro světovou literaturu, Praha: SPLAV!, 5/2011, pp. 47-49, se centra en el tema del plagio en la traducción literaria. Como editor y autor de la introducción checa, del epílogo español y de los comentarios, Miloslav Uličný llevó a cabo la publicación de las traducciones de las coplas españolas, realizadas por Antonín Pikhart y encontradas en el archivo del Museo de la Literatura Checa, con el título Španělské lidové popěvky. Sestavil a přeložil A. Pikhart. Vybral a upravil Miloslav Uličný. Praha: Jalna, 2011, p. 214 para celebrar el 150 aniversario del nacimiento del traductor. Entre las demás actividades académicas de Miloslav Uličný figuran la estancia en la capital española (del 24 al 30 de septiembre) con el objetivo de buscar los originales españoles de las traducciones de Pikhart en la Biblioteca Nacional de Madrid para la edición bilingüe de Španělské lidové popěvky, la ponencia "Gaučovský epos Martín Fierro" sobre el tema de la poesía gaucha centrada en cuatro versiones checas del poema y expuesta para estudiosos de la tercera edad el 4 de noviembre en el Instituto de Traductología y basada en el artículo de Uličný, M. "České verze gaučovského eposu Martín Fierro”, in: Plav: Měsíčník pro světovou literaturu, 1/2008, pp. 44-49; la participación en la encuesta realizada entre los hispanistas y publicada bajo el título "Můj překladatelský sen. 
Španělsko a Evropa v pohybu - ale kam?", in: PROSTOR, 92, 2011, con el objetivo de averiguar qué obra española merece ser traducida al checo; la colaboración en el programa Verše Federica Garcíi Lorky. Vuelvo por mis alas / Vracím se pro svá kř́lda (Federico García Lorca slovem - hudbou - pohybem) dirigido por Petr Vít y organizado por el Instituto Cervantes de Praga el 1 de junio de 2011; y la participación como invitado especial en la tertulia organizada por Luces de Bohemia el 21 de noviembre de 2011 en Praga. Respecto a la labor traductiva, Miloslav Uličný ha realizado las siguientes traducciones checas: Walsh, María Elena, "La vaca estudiosa / Učená kráva", Boletín argentino, 4/2011, pp. 11-12; y Yevtushenko, Yevgueni, Babí jar, sobre la traducción usada por Dmitri Shostakóvich como libreto para la 13 sinfonía Babí jar, Smetanova Litomyšl. 53 Festival Internacional de Ópera, el 29 de junio de 2011. Con ocasión de la publicación de la traducción española del poema Máj realizada por Miloslav Uličný, Miroslav Rozkošný hizo una entrevista con el traductor para la revista regional de la ciudad de Holešov titulada "Rozhovor s básníkem, překladatelem a pedagogem doc. PhDr. Miloslavem Uličným”, Holešovsko: Regionální zpravodajský čtrnáctideník, 8/2011,p. 20. El mismo año, Miloslav Uličný colaboró con el entrevistador en la preparación del artículo inicial "Rodové kořeny mají v Pravčicích", Pravčické noviny, enero de 2012 de un serial sobre los importantes linajes del municipio de Pravčice facilitando datos sobre sus antecedentes y participando en la redacción del texto. En cuanto a la propia obra, Miloslav Uličný publicó cinco romances sobre el tema de los traductores y la tarea de traducir escritos entre 1997 y 2007 en la Casa del Traductor de Tarazona bajo el título "Romancero turiasonense", Herméneus, 13/2011.

Lic. Miguel Cuenca publicó dos artículos: uno en el libro editado por Jana Králová "Posibilidades y límites de la comunicación intercultural titulado Překladovost y Posun: ¿Causa o consecuencia?”, pp. 79-83 y el otro, "La literatura checa vista desde España (1939-2000)”, in: Zborník Pedagogickej fakulty Univerzity Komenského, Philologia XXI - Supplementum II, Bratislava: Univerzita Komenského, 2011,pp. 237-241. Mgr. Vanda Obdržálková se incorporó al Departamento de Español del Instituto de Traductología.

Mencionando las memorias de licenciatura, Romana Bičíková concluyó Vlastní jména jako potenciální projev „cizosti“ v překladu neliterárního [Los nombres propios como posible representación de "lo ajeno" en la traducción del texto no literario]; Zuzana Mazancová, Rétorické figury v překladu neliterárních texti̊ [Figuras retóricas en la traducción de textos no literarios]; Vendula Procházková, Vyjadřování mezipropozičních vztahů $v$ překladu kunsthistorických texti̊ [¿Cómo expresar las relaciones interproposicionales en la traducción de textos de historia del arte?] y Martina Tihelková Rétorické figury $v$ překladech politických projevi̊ (70. a 80. léta 20. století) [Figuras retóricas en las traducciones de discursos políticos, en los años 70 y 80 del siglo XX]. En lo que se refiere a los trabajos de Fin de Grado, Tereza Bocková presentó la traducción comentada Martínez M.A., Contribuciones Iberoamericanas al mundo: Botánica, Medicina, Agricultura; Romana Marksová, Frida Kahlo, 1907-2007 y Marie Šindelářová, Historia de la música española.

Terminando con el programa Erasmus, cuatro alumnos de la sección de español pudieron realizar una estancia académica de larga duración en distintas universidades españolas, acogiéndose a las becas de este programa.

Durante el año 2012, los miembros del Departamento de Español del Instituto de Traductología de la Facultad de Filosofía y Letras de la Universidad Carolina de Praga realizaron las siguientes actividades académicas:

La Prof. PhDr. Jana Králová, CSc., publicó los siguientes artículos: sobre el tema de las posibilidades y límites de la comunicación intercultural "Possibilities and Boundaries for Intercultural Communication", in: Intercultural Inspirations for Language Education. Spaces for Understanding, Universidad de Hradec Králové, 2012, pp. 56-63; otro dedicado al papel del traductor "¿Qué habría sido del mundo si no hubieran existido los traductores?" in: Al humanista, traductor y maestro Miguel Ángel Vega Cernuda, Madrid, Dykinson, 2012, pp. 71-80; otro que se centra en el trasvase de los textos dramáticos "Estudio de traducciones del texto dramático: impulsos teóricos" in: La traducción en las artes escénicas, Madrid, Dykinson, 2012, pp. 45-55; otro que enfatiza en los textos turísticos "Breve contraste de las imágenes del país valenciano en Chequia a través de la traducción y a través de textos de la red", in: Las letras valencianas en la literatura universal. Problemas de recepción y traducción: el paisaje y el tiempo, Sevilla, Bierza, 2012, pp. 169-178; y por último 
un trabajo en colaboración con M. Furlan “A Multifacetica Realidade da Linguagem", in: Scientia Traductionis, 11/2012, pp. 172-196.

El Lic. Miguel Cuenca Drouhard publicó el artículo titulado "La posición de la literatura checa en el polisistema literario español" que apareció en el libro editado por Pilar Martino Caleidoscopio de traducción literaria, Madrid, Dykinson, 2012, pp. 57-62. Asimismo, reseñó el libro České překlady francouzské literatury (1960-1969) [La traducción checa de la literatura francesa (19601969)] (2010) redactado por Kateřina Drsková. In: Herméneus, 14/2012, Universidad de Valladolid, pp. 287-289.

La Mgr. Vanda Obdržálková presentó los resultados de su tesis doctoral en la reunión del Grupo para la Lingüística Contrastiva de las Lenguas Romances. Ha reseñado el libro Documentos de trabajo de Lingüística teórica y general escrito por Lorenzo Hervás en 2011. In: Linguistica Pragensia, 1/2012, pp. 53-56.

El Doc. PhDr. Miloslav Uličný participó en la publicación de la edición bilingüe de una traducción al alemán, escrita a mano, del poema checo Máj (Der Mai) de K. H. Mácha elaborada por B. A. Rambousek y hallada por el profesor en el fondo personal del traductor A. Pikhart. Es autor del prefacio (pp. 9-34) y de la lista de las traducciones alemanas del poema (pp. 35-36). “Máj = Der Mai”, in: Praha: Splav!, 2010, pp. 179. Publicó una selección de sus poemas escritos en español titulada "Romancero Turiasonense" in: Herméneus, Universidad de Valladolid, 14/2012, pp. 347-360.

La PhDr. Petra Vavroušová se incorporó a los estudios de doctorado en Traductología. Participó en el proyecto literario dirigido por Tomáš Dimter, en concreto en la redacción lingüística de la traducción de la novela de Christina Koenig Ráj poníků. Štěstí má čtyři nohy [Paraíso de los ponis. La suerte tiene cuatro patas] publicado en la editorial Mladá fronta de Praga. Además, en el congreso Česká romanistika v evropském kontextu: XVI. olomoucké setkání romanistů [Romanística checa en el contexto europeo: XVI encuentro de romanistas en Olomouc], celebrado entre 23 y 24 de noviembre, presentó la ponencia "Sedm tváří translatologie. Teorie překladu a tlumočení prizmatem současných španělských translatologů" [Siete caras de la traductología: La teoría de la traducción e interpretación desde la óptica de los investigadores españoles] y en el Encuentro de Hispanistas, Brno 2012, celebrado entre 30 de noviembre y 1 de diciembre, la contribución "Santoyo a jeho recepce v českém prostředí. La Malinche a El Tostado aneb tlumočníci lodních výprav a překladatelský metajazyk" [Santoyo y su recepción en el ambiente checo. La Malinche y El Tostado, o sea, los intérpretes de navío y el metalenguaje traductor]. Asimismo, dirigió el proyecto VG151: Teorie překladu a tlumočení prizmatem současných španělských translatologů [Beca interna $n^{\circ}$ 151: Teoría de la traducción e interpretación desde la óptica de los investigadores españoles contemporáneos] subvencionado por la Facultad de Filosofía y Letras de la Universidad Carolina de Praga en el marco de las becas internas cuya jefa académica fue la profesora Jana Králová; el propósito del proyecto es presentar al ambiente checo la generación fundadora de la traductología española.

Mencionando las memorias de licenciatura, Eva Vilches concluyó Rosa Rabadán a její př́nos pro vývoj translatologie [Rosa Rabadán y su contribución al desarrollo de la traductología] y Jana Masaříková, Dva české překlady románu José Eustasia Rivery La Vorágine [Dos traducciones checas de la novela La vorágine de José Eustasio Rivera]. Alžběta Malkovská defendió el trabajo Strategie tlumočníka při simultánním tlumočení do mateřštiny a do aktivního cizího jazyka [Las estrategias del intérprete en la interpretación simultánea hacia la lengua materna y hacia la lengua activa] y Lenka Tesárková, Rétorické figury $v$ prekladech současné venezuelské publicistiky se zaměřním na Jana Rudolfa Slabého [Las figuras retóricas en las traducciones de los textos periodísticos contemporáneos de Venezuela en relación con Jan Rudolf Slabý] y les fue otorgado el título "PhDr." (el llamado pequeño doctorado). En lo que se refiere a los trabajos de Fin de Grado, Eva Halanová presentó la traducción comentada Guía de recursos para ciudadanos extranjeros residentes en Roquetas de Mar; Jakub Herák, El imperio ultramarino español; Kateřina Kuncová, La Doma Vaquera: Del campo a las pistas de concurso; Lucie Trägerová, Historia de la literatura hispanoamericana y Martina Uková, Guía Total: Baleares (Eivissa, Menorca, Formentera).

Terminando con el programa Erasmus, siete alumnos de la sección de español pudieron realizar una estancia académica de larga duración en distintas universidades españolas, acogiéndose a las becas de este programa. 


\section{Actividades del Departamento de Español del Instituto de Traductología en 2013}

Durante el año 2013, los miembros del Departamento de Español del Instituto de Traductología de la Facultad de Filosofía y Letras de la Universidad Carolina de Praga llevaron a cabo las siguientes actividades académicas:

La Prof. PhDr. Jana Králová, CSc. redactó el prólogo del libro Los franciscanos y el contacto de lenguas y culturas, Praha, Karolinum, 2013, pp. 7-12 editado por Antonio Bueno García. Entre otros artículos publicados podemos mencionar "Překlad jako kulturní (sebe)reflexe" [Traducción como (auto)reflexión cultural], in: Vědecký výzkum a výuka jazyků V. Komunikační sebereflexe a kompetence, Hradec Králové, 2013, pp. 27-343; "La recepción de la obra de Jiří Levý en los países hispánicos y lusófonos", in: Diversidad lingüística del español, 2013, pp. 191-169 y la reseña de la traducción inglesa de la obra Umění překladu [El arte de la traducción] Jiř́ Levý, The Art of Translation, traducido por Patrick Corness con el prólogo escrito por Zuzana Jettmarová. Benjamins Translation Library, 97, Amsterdam-Philadelphia, John Benjamins, 2011, in: Herméneus, 15/2013, pp. 365-368. Es profesora colaboradora del programa de doctorado interuniversitario "Traductología, traducción profesional y audiovisual" (Universidad de Valladolid y Universidad de Alicante). Realizó varias estancias en el extranjero: entre el 18 y 23 de marzo en la Universidad de Kragujevaci, Serbia y en abril en la Universidad de León. Asimismo tomó parte como miembro del tribunal de defensa de la tesis doctoral de Javier García Albero en Universidad de Alicante. En la misma universidad, Jana Králová y Vanda Obdržálková forman parte del equipo de investigación del proyecto TRALICOVA. Jana Králová y Miguel Cuenca Drouhard eligieron los textos más representativos y significativos del traductólogo checo Jiří Levý y gracias a ellos el público académico español puede leer sobre sus conceptos en el libro Jiři Levý: una concepción (re)descubierta, Vertere: Monográficos de la revista Herméneus, 15/2013, Soria, Diputación Provincial de Soria. La obra fue incluida entre las monografías de prestigio de la Universidad Carolina de Praga.

El Lic. Miguel Cuenca participó como traductor también en el libro Libri magistri muti sunt. Pocta Jaroslavě Kašparové, preparado por Alena
Císařová Smítková, Andrea Jelínková y Milada Svobodová, Praha, Knihovna AV ČR.

PhDr. Anežka Charvátová se incorporó al Departamento de Español del Instituto de Traductología. En noviembre participó en el congreso traductor XII Simposio de Traducción Literaria 2013 en Cuba donde pronunció su ponencia "Cómo rugen en checo Tres tristes tigres".

Mgr. Vanda Obdržálková leyó y defendió en junio su tesis doctoral titulada Odstavec jako kognitivní jednotka výstavby neliterárních texti̊ [E] párrafo como unidad cognitiva en la estructura de textos no literarios]. También publicó el artículo "El párrafo como unidad sintáctico-formal y temática de textos expositivo-argumentativos en checo y en español: enfoque contrastivo y traductológico", in: Sendebar, 24/2013, pp. 127-150.

El Doc. PhDr. Miloslav Uličný publicó la traducción al checo del poema Al salir de la cárcel de Fray Luis de León: Při opuštění žaláře, in: Decíamos ayer. XVI Encuentro de Poetas Iberoamericanos. Antología en homenaje a Fray Luis de León. Antólogo y coordinador Alfredo Pérez Alencart, Salamanca, Edifsa 2013, pp. 71. Fue nombrado miembro honorífico por la asociación Jednota překladatelů a tlumočníků (JTP) [Unión de Intérpretes y Traductores] por su labor traductiva y la gestión del Club de la Cultura de Traducción.

La PhDr. Mgr. Petra Vavroušová llevó a cabo, como editora, la publicación Sedm tvárí translatologie: Teorie překladu a tlumočení prizmatem současných španělských translatologů [Siete caras de la traductología: La teoría de la traducción e interpretación desde la óptica de los investigadores españoles], Praha, Karolinum, 2013. Producto final del proyecto subvencionado por la Facultad de Filosofía y Letras de la Universidad Carolina de Praga, cuyo objetivo es presentar la generación fundadora de los Estudios de Traducción en España al público (académico) checo. El libro fue presentado en el Instituto Cervantes de Praga. También reseñó el libro de Juan Antonio Albaladejo Martínez La literatura marcada: problemas de traducción y recepción ejemplificados a través del teatro popular vienés, redactando el texto "Reseña: Devolver, siempre que sea posible, marca por marca", in: Linguistica Pragensia, 1/2013, pp. 77-79. Además, escribió el artículo “Julio-César Santoyo y su recepción en la República Checa. El Tostado, o sea, el metalenguaje traductor", y "La Malinche, o sea, los intérpretes de navíos", in: Setkání hispanisti̊. Encuentro de hispanistas, 
Brno, 2012, pp. 153-163. Entre otros, participó en el proyecto literario de estudiantes dirigido por Tomáš Dimter y formó parte del equipo que tradujo del alemán al checo el libro de Sylvia Henlein Bláznivá teta a já aneb „Rychle pryč! “ rekla teta Matylda [La tía loca y yo, o sea, ¡Nos vamos!, dijo la tía Matylda] publicado en la editorial Mladá Fronta de Praga. En lo que se refiere a los congresos, presentó su trabajo "The German language and its potential as a cultural mediator in the translation" en $7^{\text {th }}$ EST Congress: Germersheim, Panel 7: Indirect Translation: state-of-theart and future research avenues, celebrado entre el 29 de agosto y el 1 de septiembre en Alemania, y pronunció su ponencia "Švejk y sus aventuras en la prensa española” en el III Congreso Internacional Studia Romanistica Beliana. Cultura, lengua y literatura en el contexto espacial y temporal: aspectos interdisciplinarios, Banská Bystrica, celebrado entre el 10 y 11 de octubre.

La Mgr. Jana Mrkvová se incorporó en los estudios de doctorado en Traductología. Formó parte del equipo que llevó a cabo la publicación del anteriormente mencionado libro Sedm tváří translatologie y tradujo el estudio de Raquel Merino Álvarez titulado Dramatické texty přeložené a cenzurované ve frankistickém Španělsku (šedesátá léta): divadlo a film jako kontrolovaná představení [Textos dramáticos traducidos y censurados en la España de Franco (años sesenta): el teatro y el cine espectáculos controlados]. Asimismo participó en la presentación de la publicación.

Mencionando las memorias de licenciatura, Romana Buaiscia concluyó Francisco Ayala a jeho prínos $k$ vývoji translatologie [Francisco Ayala y su contribución al desarrollo de la traductología] y Eliška Zajícová, Jazyková a kulturní specifičnost české filmové produkce $v$ titulkovaném exportu [La especificidad lingüística y cultural de la producción cinematográfica checa en los subtítulos]. En lo que se refiere a los trabajos de Fin de Grado, Jindra Guttenbergová presentó la traducción comentada Anatomía del miedo; Anna Perglerová, Pablo de Sarasate; Eliška Vořřšková, Sefarad: los judíos de España y Lenka Zábojová, Fonetometría: una propuesta de protocolo.

Terminando con el programa Erasmus, dos alumnos de la sección de español pudieron realizar una estancia académica de larga duración en distintas universidades españolas, acogiéndose a las becas de este programa.

\section{Actividades del Departamento de Español del Instituto de Traductología en 2014}

Durante el año 2014, los miembros del Departamento de Español del Instituto de Traductología de la Facultad de Filosofía y Letras de la Universidad Carolina de Praga realizaron las siguientes actividades académicas:

La Prof. PhDr. Jana Králová, CSc., ha publicado el capítulo "Antología de textos traductológicos: problema de comunicación intercultural" en la monografía colectiva Lingua, cultura e media, pp. 465-476. En octubre realizó una estancia en la Universidad del País Vasco. En lo que se refiere a su membresía en los proyectos de investigación internacionales, forma parte del equipo TRALIMA en la Universidad del País Vasco. Participó como ponente en las conferencias Traducción y Humanismo en Soria y en las IV Jornadas HISTRAD (Historia de la traducción) de Tarazona.

El Lic. Miguel Cuenca leyó y defendió su tesis doctoral titulada Influencia del polisistema cultural español en la traducción de literatura checa durante la segunda mitad del siglo XX.

La PhDr. Anežka Charvátová tradujo al checo la novela de Carlos Fuentes Vlad y la novela Tři truchlivý tigři [Tres tigres tristes] de Guillermo Cabrera Infante. Asimismo participó como moderadora de varias difusiones por la radio, presentaciones de nuevas traducciones al checo o charlas organizadas en el Instituto Cervantes de Praga.

El Doc. PhDr. Miloslav Uličný elaboró un informe sobre el hallazgo de un manuscrito del sacerdote Josef Hausmann Hořínský, de 50 páginas, fechado 1850, dedicado al romancero castellano, con tres romances cidianos y uno del último rey godo, traducidos al checo. Se trata de las primeras muestras de versiones checas del romancero caste1lano: "Rukopisné překlady španělských romancí v knihovně Národního muzea" [Las traducciones de los romanceros españoles en la Biblioteca del Museo Nacional]. In: Sborník Národního muzea v Praze. ̌̌ada C - Literární historie, vol. 59, 3-4/2014, Praha, Národní muzeum, pp. 45-50. Vertió al checo el poema El crimen fue en Granada de Antonio Machado: V Granadě stal se zločin. In: Frankovy děti. Plav, měsíčník pro světovou literatura, 8/2014, pp. 18-21 y en el mismo número de dicha revista publicó en checo una reflexión del poeta español: "Válku jsme prohráli. Ale lidsky vzato si tím nejsem tak jistý" [Hemos perdido la 
guerra. Pero desde el punto de vista humano, no estoy tan seguro], pp. 22-25.

La PhDr. Mgr. Petra Vavroušová tradujo una selección del Epistolario de Luis Cernuda al checo, in: Frankovy děti. Plav: Měsíčník pro světovou literaturu, 8/2014, pp. 44-49. Participó como ponente en el V Simposio Internacional de Hispanistas, Encuentros 2014. Relecturas y nuevos horizontes en los estudios hispánicos, celebrado entre 6 y 9 de mayo en Ustron, Polonia con la ponencia "Recepción recíproca de las teorías de la traducción checa e hispana"; luego en las I Jornadas sobre hispanismo, edición y cultura digital en České Budějovice, celebrado entre el 26 y 28 de mayo, presentando "Las aventuras del buen soldado Švejk por tierras españolas"; y por último, en Jeronýmovy dny [Días de San Jerónimo], celebrados entre 7 y 8 de noviembre, en Praga con la ponencia "Osudy dobrého vojáka Švejka ve španělských překladech" [Las aventuras del buen soldado Švejk en las traducciones españolas]. Comenzó a dirigir el proyecto de dos años titulado Překlad jako most mezi dvěma břehy [Traducción como puente entre dos orillas], subvencionado por la Facultad de Filosofía y Letras de la Universidad Carolina de Praga, cuyo objetivo es presentar al público checo las tendencias metodológicas y puntos de interés de la traductología en Iberoamérica; la jefa académica del proyecto fue Jana Králová. Petra Vavroušová y Vanda Obdržálková formaron parte del equipo que llevó a cabo el proyecto Diccionario para el trabajo intercultural en siete mutaciones lingüísticas cuyo fruto es, entre otros, Česko-španělský Slovník pro interkultuní práci. Diccionario checo-español: trabajo intercultural, Praha, in: Báze, 2014.

La doctoranda Mgr. Jana Mrkvová también participó en ya mencionado V Simposio Internacional de Hispanistas con la contribución titulada "Antonín Pikhart, el fundador del hispanismo traductivo checo". Publicó un artículo sobre el traductor A. Pikhart y el análisis de su biblioteca personal en la revista del Museo Nacional de Praga: "K osobní knihovně právníka, básníka a překladatele Antonína Pikharta", in: Sborník Národního muzea $v$ Praze. (Acta Musei Nationalis Pragae. Series C, Historia Litterarum.), 59, 3-4/2014, pp. 25-30.

Se incorporaron a los estudios de doctorado en Traductología Antonio Rivas que publicó la versión española del libro Paciencia con Dios. Cerca de los lejanos escrito por Tomáš Halík en la editorial Herder, y en Didáctica del español Margarita Gianino.
En cuanto a los trabajos de Fin de Grado, Marcela Kubová presentó la traducción comentada Registro de la bibliografía franciscana que se encuentra en las bibliotecas colombianas: aproximación histórica y Simona Šlosárová, Filosofía e historia en la práctica de la traducción.

Terminando con el programa Erasmus, tres alumnos de la sección de español pudieron realizar una estancia académica de larga duración en distintas universidades españolas, acogiéndose a las becas de este programa.

\section{Actividades del Departamento de Español del Instituto de Traductología en 2015}

Durante el año 2015, los miembros del Departamento de Español del Instituto de Traductología de la Facultad de Filosofía y Letras de la Universidad Carolina de Praga realizaron las siguientes actividades académicas:

La Prof. PhDr. Jana Králová, CSc., realizó una estancia en la Universidad del País Vasco en octubre. Es miembro del proyecto internacional 2015-2017: FF12014-59140P: Catalogación y estudio de las traducciones de los dominicos españoles, subvencionado por el Programa estatal de la investigación científica y técnica de excelencia. Subprograma estatal de generación de conocimiento, Ministerio de Economía y Competitividad, España. También figura, junto con D. Mraček y S. Rubáš como editora del número monotemático AUC Philologica 3/2015, Translatologica Pragensia IX, Praha: Karolinum.

Jana Králová y Petra Vavroušová han colaborado con el Instituto de Lenguas Románicas en la organización del congreso Las palabras (des) atadas - Encuentro de hispanistas 2015 celebrado entre 16 y 17 de octubre en Praga. En este encuentro, los miembros del Instituto de Traductología presentaron sus ponencias: Anežka Charvátová "Revisión del pasado en la literatura contemporánea chilena y argentina: convergencias y divergencias"; Jana Mrkvová "La traducción audiovisual en España y América Latina: inspiración metodológica para el ámbito checo" y Petra Vavroušová "La traducción e interpretación en la historia cultural de América Latina".

PhDr. Anežka Charvátová participó como ponente en el congreso traductológico Jan Zábrana: básník, překladatel, čtenár [Jan Zábrana: poeta, traductor, lector], celebrado entre el 6 y 7 de noviembre, con la comunicación “Zábranovy 
překlady N. Parry: výchozí text jako zrcadlo překladatelovy duše?" [Las traducciones de N. Parra por Jan Zábrana: ¿el texto de partida como espejo del alma del traductor?] y en el congreso sobre la República Dominicana, celebrada el 10 de diciembre, con la charla "La fiesta del Chivo de Mario Vargas Llosa y la República Dominicana". Además, participa en el proyecto Podoby současné argentinské literatury [Las facetas de la literatura argentina contemporánea], subvencionado por la Facultad de Filosofía y Letras de la Universidad Carolina de Praga, y en el proyecto internacional de investigación La recepción europea de la literatura latino-americana moderna. Los casos de Albania, Bulgaria, Croacia, Eslovaquia, Eslovenia, Grecia, Hungría, Italia, Polonia, Portugal, República Checa, Rumania y Serbia. Tradujo al checo dos novelas de Umberto Eco, Foucaultovo kyvadlo [El péndulo de Foucault] y Nulté číslo [Número cero] y también Hluk padajících věcí [El ruido de las cosas al caer] de Juan Gabriel Vásquez.

El Doc. PhDr. Miloslav Uličný escribió la reseña del novísimo arreglo checo de una vetusta adaptación del Quijote para la juventud: "Don Quijote recyklovaný" [Don Quijote reciclado], in: Plav, měsíčník pro světovou literaturu, 3/2015, pp. 53-56. Publicó el prólogo y traducción de cuatro poemas en ocasión del quinto centenario del nacimiento de Santa Teresa de Jesús: "Terezie z Ávily toužila spatřit Boha" [Teresa de Ávila anheló ver a Dios], in: Naše rodina, 14/2015, pp. 12-13. Colaboró con Petr Jan Vinš en la elaboración del prólogo que precede la traducción de dos poemas de Fray Luis de León vertidas al checo por el profesor: "Učený hlas španělské mystiky. Z tvorby Ludvíka Leónského" [La voz erudita de la mística española. De la creación de Ludvík León], in Naše rodina, 34/2015, pp. 12-13. Fue publicada su traducción de Memorias del abuelo de un punk de Ezequiel Blanco junto con el retrato del autor elaborado por el traductor: "Paměti pankáčova dědečka" [Memorias del abuelo de un punk], in: Nová vlna, p. 126. Ha elaborado una traducción de cien romances catalanes acompañada de un estudio sobre los catalanes y la literatura catalana: "V Barceloně, velkém městě. Sto katalánských romancí" [En Barcelona, ciudad grande. Cien romances catalanes], Nová vlna, p. 132. Tradujo poesías de Santa Teresa de Jesús publicadas con un epílogo escrito por el traductor: Sebe ve mně hledat musís. Básně svaté Terezie od Ježíše [A ti en mí debes buscar. Poemas de Santa Teresa de
Ávila], Kostelní Vydří: Karmelitánské nakladatelství, p. 80. Pasó al checo el conjunto de sonetos de Edward de Vere, atribuidos hasta hace poco a W. Shakespeare y ha elaborado un prólogo para lectores y epílogo para traductólogos: "Sonnets/ Sonety" [Sonetos], Nová vlna, p. 220. Aparte de la labor de traducción, Miloslav Uličný participó con una contribución pronunciada en español en la presentación del libro de Gabriel Rosenzweig "Procurando contactos a la literatura mexicana" (Alfonso Reyes - Zdeněk Šmíd, Correspondencia 1932-1959) organizada en el Instituto Cervantes de Praga en marzo y presentó dos de sus traducciones, Memorias del abuelo de un punk y Cien romances catalanes, en el mismo lugar en noviembre. Su Majestad el Rey, Don Felipe VI le otorgó la Orden del Mérito Civil, con el grado de Comendador.

PhDr. Mgr. Petra Vavroušová se incorporó al Departamento de Español y Alemán del Instituto de Traductología. Llevó a cabo, como editora, la publicación del libro Překlad a tlumočení jako most mezi kulturami [Traducción e interpretación como puente entre culturas], Praha, Karolinum, 2015. Producto final del proyecto subvencionado por la Facultad de Filosofía y Letras de la Universidad Carolina de Praga cuyo objetivo es presentar las cuestiones traductológicas desarrolladas actualmente en Iberoamérica. Redactó el artículo "Traducción e interpretación como puente entre culturas. Inspiración (metodológica) para la traductología checa", in: Nuevos horizontes en los Estudios de Traducción e Interpretación (Comunicaciones completas), pp. 430-438. Tradujo del alemán al checo la novela Čmeláci v srdci [Abejorros en el corazón] de Petra Hüllsmann. En cuanto a los actos académicos, participó en el VII Congreso Internacional de la Asociación Ibérica de Estudios de Traducción e Interpretación (AIETI), Universidad de Málaga, celebrado del 29 al 31 de enero con la comunicación "De la traducción e interpretación como puente entre culturas. Inspiración (metodológica) para la traductología checa" y en las II Jornadas sobre Hispanismo, Edición y Cultura Digital, Universidad de Bohemia del Sur, České Budějovice, celebradas entre el 23 y 24 de abril, con la charla "Traducción e interpretación como un puente entre culturas" y preparó también taller de interpretación.

La doctoranda Jana Mrkvová concluyó la traducción del artículo de Daniel Ricardo Yagolkowski: "Traducción del humor en literatura 
y cine" [Přreklad humoru v literatuře a ve filmu] para el mencionado libro Překlad a tlumočení jako most mezi kulturami. Pronunció una charla sobre el traductor A. Pikhart y su biblioteca personal en la sesión TRALIMA/ITZULIK doctorandos organizada en la Universidad del País Vasco.

Se incorporaron a los estudios de doctorado en Didáctica del español Iván Alonso y Petr Puffer

Mencionando los Trabajos de Fin de Máster, Lenka Pospíšilová concluyó Rozdíly v hodnocení kvality tlumočení [Las diferencias en la evaluación de la calidad de interpretación]; Marie Šindelářová, Orální historie tlumočení v Československu pred rokem 1989 [La historia oral de la interpretación en Checoslovaquia hasta 1989]; Martina Uková, Role tlumočníka v zónách konfliktu [El papel del intérprete de las zonas de conflicto] y Lenka Zábojová, Problematika překládání divadelních her se zaměrením na školní divadlo. Komentovaný preklad souboru dramat
Davida Llorenteho Los árboles dormidos [La problemática de la traducción de las obras teatrales centrándose en el teatro escolar. La traducción comentada de las obras de teatro de David Llorente]. En lo que se refiere a los trabajos de Fin de Grado, Veronika Sochorová presentó la traducción comentada La cerámica precolombina: el barro que los indios hicieron arte y Alena Schindlerová, Un niño con autismo en la familia. Guía básica para familias que han recibido un diagnóstico de autismo para su hijo o hija.

Terminando con el programa Erasmus, seis alumnos de la sección de español pudieron realizar una estancia académica de larga duración en distintas universidades españolas, acogiéndose a las becas de este programa.

por Petra Vavroušová y Jana Mrkvová (Praga) (Escrito en español por las autoras) 